\title{
Differential responses to tritiated thymidine incorporation into DNA between mouse embryonic neural stem cells and fibroblasts
}

\author{
Sofiane Mokrani ${ }^{1}$, Christine Granotier-Beckers ${ }^{1, *}$, Olivier Etienne ${ }^{1}$, Christian Grisolia ${ }^{2}$, and \\ François Boussin ${ }^{1}$ \\ ${ }^{1}$ CEA, JACOB, IRCM, INSERM U967, Laboratoire de Radiopathologie, Université Paris Diderot \\ Sorbonne Paris Cité, Université Paris XI, 92260 Fontenay-aux-Roses, France \\ ${ }^{2}$ CEA, DRF, IRFM, SI2P, GCFPM, 13115 Saint-Paul-lez-Durance, France
}

Tritium is the radioactive isotope of hydrogen with a low beta energy emission. It is generated naturally or released by nuclear power plants. Tritium has a persistent and ubiquitous distribution in the environment and different biological systems.

Epidemiological data and experiments on animal models have shown the damaging effects of tritiated compounds [1-3], but their impact on the developing brain remains poorly known. The developing brain is particularly radiosensitive because of the genetic damage induced in the Neural Stem and Progenitor Cells (NSPCs) which generate most of brain cells.

Previous results in the laboratory have described the cellular and genetic effects of tritiated thymidine $\left({ }^{3} \mathrm{H}-\mathrm{T}\right)$ on primary cultures of human embryonic NSPCs. A better understanding of the molecular mechanisms involved in the genotoxicity of tritium is now required to define the individual sensitivity factors to tritium incorporation.

In this study, we used primary cultures of NSPCs isolated from mouse embryonic brain cortex after 14 days of gestation. We characterized the chromosome instability induced by increasing doses of ${ }^{3} \mathrm{H}-\mathrm{T}$ incorporation into the DNA during replication. Our results show that mouse and human embryonic NSPCs exhibit similar responses to ${ }^{3} \mathrm{H}-\mathrm{T}$ incorporation.

Primary cultures of Mouse Embryonic Fibroblasts (MEF) were also isolated from skin at the same developmental stage.

Using cellular autoradiography we revealed that ${ }^{3} \mathrm{H}-\mathrm{T}$ induces high chromosome instability in MEF than NSPCs. We also observed significantly higher radiosensitivity of MEF as compared to NSPCs after $\gamma$-radiation exposure.

These data evidence significant differences in the DNA damage responses of MEF and NSPCs. In order to further investigate the mechanisms involved, we have compared the chromosome instability induced by tritium incorporation in NSPC and MEF obtained from mice deficient for different DNA repair pathways.

\section{References}

* Corresponding author: christine.granotier@cea.fr 
1. S. Zamenhof, E. van Marthens, Radiat Res, 77 (1979)

2. SJ. Bursian, DF. Cahill, JW. Laskey, LN. Parker, Int J Radiat Biol Relat Stud Phys Chem Med, 27,5 (1975)

3. B. Wang, H. Takeda, WM. Gao, XY. Zhou, T. Odaka, H. Ohyama, Health Phys. 77, 1(1999). 